\title{
Active two-terminal devices as local oscillators for low-noise receiver systems at submillimeter wave frequencies
}

\author{
H. Eisele, R. Kamoua, G. I. Haddad and C. Kidner, Ann Arbor and Stony Brook, U.S.A.
}

Contents: The power capabilities of three different two-terminal devices, GaAs IMPATT diodes, InP Gunn devices and GaAs TUNNETT diodes are evaluated. Two different selective etching technologies have been employed to fabricate devices on either a diamond heat sink or an integral heat sink. The reported RF power levels in fundamental mode are $20 \mathrm{~mW}$ at $120 \mathrm{GHz}$ and $15 \mathrm{~mW}$ at $135 \mathrm{GHz}$ for D-band GaAs IMPATT diodes, $21 \mathrm{~mW}$ at $120 \mathrm{GHz}$, $17 \mathrm{~mW}$ at $133 \mathrm{GHz}$ and $8 \mathrm{~mW}$ at $155 \mathrm{GHz}$ for D-band InP Gunn devices and up to $35 \mathrm{~mW}$ around $103 \mathrm{GHz}$ for W-band $\mathrm{GaAs}$ TUNNETT diodes. Typical dc to RF conversion efficiencies range from $0.9 \%$ up to over $4.0 \%$. In second harmonic mode power levels of $0.25 \mathrm{~mW}$ at $223 \mathrm{GHz}$ were measured from TUNNETT diodes and $0.4 \mathrm{~mW}$ at $220 \mathrm{GHz}$ from a Gunn device.

\section{Aktive Zweipol-Bauelemente als Lokaloszillatoren für rauscharme Empfängersysteme im Frequenzgebiet der Submillimeterwellen}

Übersicht: Die Leistungsfähigkeit dreier verschiedener Zweipolbauelemente, GaAs-IMPATT-Dioden, InP-Gunn-Bauelemente und GaAs-TUNNETT-Dioden, wird untersucht. Zwei unterschiedliche Herstellungsverfahren mit selektivem Ätzen wurden eingesetzt, um Bauelemente auf einer Diamant- bzw. integrierten Wärmesenke herzustellen. Hochfrequenzausgangsleistungen von $20 \mathrm{~mW}$ bei $120 \mathrm{GHz}$ und $15 \mathrm{~mW}$ bei $135 \mathrm{GHz}$ wurden mit GaAs-IMPATTDioden für das D-Band erzielt, $21 \mathrm{~mW}$ bei $120 \mathrm{GHz}, 17 \mathrm{~mW}$ bei $133 \mathrm{GHz}$ und $8 \mathrm{~mW}$ bei $155 \mathrm{GHz}$ mit InP-Gunn-Bauelementen für das D-Band und bis zu $35 \mathrm{~mW}$ um $103 \mathrm{GHz}$ mit GaAs-TUNNETT-Dioden für das W-Band. Typische Hochfrequenzwirkungsgrade lagen zwischen $0,9 \%$ und über $4 \%$. Bei der ersten Oberwelle wurden mit TUNNETT-Dioden HF-Leistungen von $0,25 \mathrm{~mW}$ bei $223 \mathrm{GHz}$ gemessen und $0,4 \mathrm{~mW}$ bei $220 \mathrm{GHz}$ mit einem GunnBauelement.

\section{Introduction}

There is a growing need for local oscillator power above $100 \mathrm{GHz}$ in radioastronomy. Although impressive progress has been demonstrated for oscillators with threeterminal devices at $\mathrm{mm}$-wave frequencies $[1,2]$ two-terminal devices still hold the greatest promise in delivering significant power levels at sub-mm-wave frequencies. This paper summarizes the recent experimental results obtained from IMPATT diodes, TUNNETT diodes and Gunn devices at frequencies above $100 \mathrm{GHz}$ and gives an overview of design procedures and fabrication technolo- gies. The experimental results on D-band InP Gunn devices agree well with simulations [3] and indicate that fundamental mode operation can be extended to the upper D-band. Since IMPATT diodes, TUNNETT diodes and Gunn devices are nonlinear devices, this paper also focuses on harmonic power extraction.

\section{Device design}

The design of the GaAs D-band single-drift flat-profile IMPATT diodes was based on an extended small-signal model for the avalanche region and a large-signal approximation for the drift region and followed the same procedure as previously used in the design of GaAs W-band diodes [4]. The design of the W-band TUNNETT diodes was based on a simplified large-signal model [5] and GaAs material parameters derived from measurements on heavily doped $\mathrm{p}^{++} \mathrm{n}^{+}$junctions and GaAs IMPATT diodes [6].

An Ensemble Monte Carlo program has been developed to simulate Gunn devices. Since a Monte Carlo method requires accurate values for a large number of material parameters, first InP W-band Gunn devices with $\mathrm{n}^{+} \mathrm{n}^{-} \mathrm{n}^{+}$structures similar to published designs were fabricated and tested. The appropriate material parameters were selected by comparing dc and high-frequency measurements with results predicted by the model [3]. During this selection process two different structures for operation at D-band frequencies were designed, one with a flat doping profile and one with a graded doping profile [3].

\section{Fabrication technology}

A lattice matched $\mathrm{Al}_{0.55} \mathrm{Ga}_{0.45} \mathrm{As}$ layer grown between the device layers and the GaAs substrate or a lattice matched $\mathrm{In}_{0.53} \mathrm{Ga}_{0.47}$ As layer grown between the device layers and the InP substrate allows the use of a selective etching technology [3, 8]. This technology gives substrateless devices on a 15 to $20 \mu \mathrm{m}$ thick integral heat sink. Figure 1 outlines the main steps in this fabrication technology. Before the epitaxial side of the MBE-, CBEor MOCVD-grown wafer is metallized with $\mathrm{Ti} / \mathrm{Pt} / \mathrm{Au}$ for 


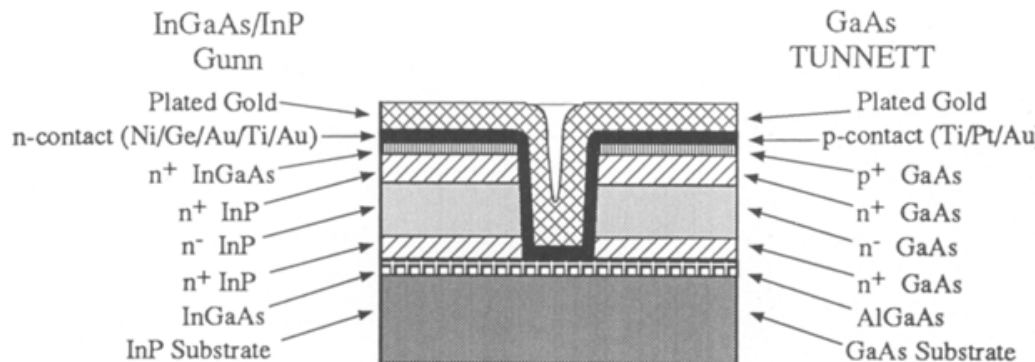

a

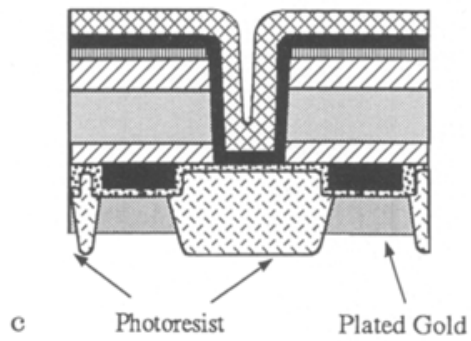

Fig. 1. Flow chart for mesa-type two-terminal device fabrication

a $\mathrm{p}^{+}$ohmic contact (TUNNETT diode) or $\mathrm{Ni} / \mathrm{Ge} / \mathrm{Au} /$ $\mathrm{Ti} / \mathrm{Au}$ for an $\mathrm{n}^{+}$ohmic contact (Gunn device), grooves are selectively etched down to the etch-stop layer (AlGaAs or InGaAs) to divide the device layers into square shaped islands. This reduces the stress in the device layers during annealing. In addition, the trenches shape the evaporated metal layers and plated gold layer of the integral heat sink thus increasing the mechanical strength of the metal layers for the subsequent processing steps after the substrate and the etch-stop layer have been removed in selective etches. The top $\mathrm{n}^{+}$ohmic contact $(\mathrm{Ni} / \mathrm{Ge} / \mathrm{Au} / \mathrm{Ti} / \mathrm{Au})$ is defined by standard lift-off technology. After an additional metallization $(\mathrm{Ti} / \mathrm{Au} / \mathrm{Ti})$ step a second photolithography process produces a hole on top of each $\mathrm{n}^{+}$ohmic contact. The top Ti layer is removed and up to $3 \mu \mathrm{m}$ of gold can be electroplated through these holes in order to ease bonding. The remaining $\mathrm{Ti} / \mathrm{Au} / \mathrm{Ti}$ layers between the contacts are removed in wet etches. Mesas are formed using a standard wet etch and the ohmic contacts are annealed on a hot plate. The heat sink is diced to give individual devices. TUNNETT diodes with nominal diameters of $25-35 \mu \mathrm{m}$ or Gunn devices with nominal diameters of $35-45 \mu \mathrm{m}$ are mounted on gold plated copper blocks.

The high operating current densities around $60 \mathrm{kAcm}^{-2}$ and corresponding high power densities in D-band IMPATT diodes require operation on diamond heat sinks. Therefore another, previously reported, selective etching technology [8] was employed in the fabrication of the IMPATT diodes. The diodes are thermocompression bonded on to metallized diamond heat sinks.

To minimize parasitic elements of the package and to find the optimum impedance transformation an open package with four stand-offs and tapered ribbons was chosen for all the IMPATT and TUNNETT diodes and for most of the Gunn devices. Some of the Gunn devices were packaged with metallized quartz rings and tapered gold ribbons.

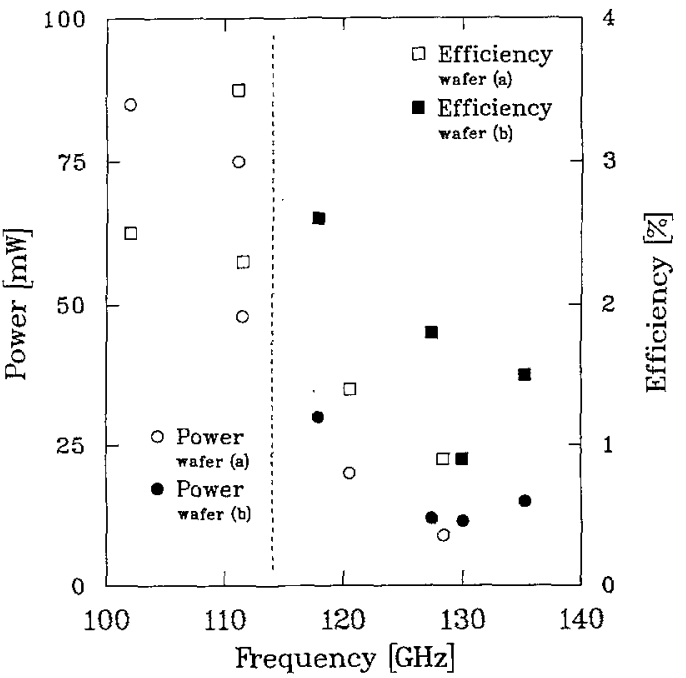

Fig. 2. Output power and efficiency versus oscillation frequency for different GaAs D-band single-drift flat-profile IMPATT diodes

\section{Experimental results}

A full-height waveguide cavity (WR-10 for W-band, WR-6 for D-band) with a resonant cap on top of the device and with a back short at one flange has been successfully used for all the two-terminal devices reported in this paper. The gold plated copper block of the heat sink forms the bottom of the waveguide.

Figure 2 compares the performance of D-band IMPATT diodes fabricated from two wafers with an active layer of a nominal width between $0.285 \mu \mathrm{m}$ and $0.28 \mu \mathrm{m}$ and of a nominal doping concentration between $2.7 \times 10^{17} \mathrm{~cm}^{-3}$ and $2.8 \times 10^{17} \mathrm{~cm}^{-3}$. Diodes made from wafer (b) exhibit slightly higher RF power levels and dc to $\mathrm{RF}$ conversion efficiencies at frequencies above $120 \mathrm{GHz}$; $20 \mathrm{~mW}$ with $1.4 \%$ at $120 \mathrm{GHz}$ and $15 \mathrm{~mW}$ with $1.5 \%$ at $135 \mathrm{GHz}$ were obtained [9].

A plot of the RF output power and dc to RF conversion efficiency versus oscillation frequency in Fig. 3 


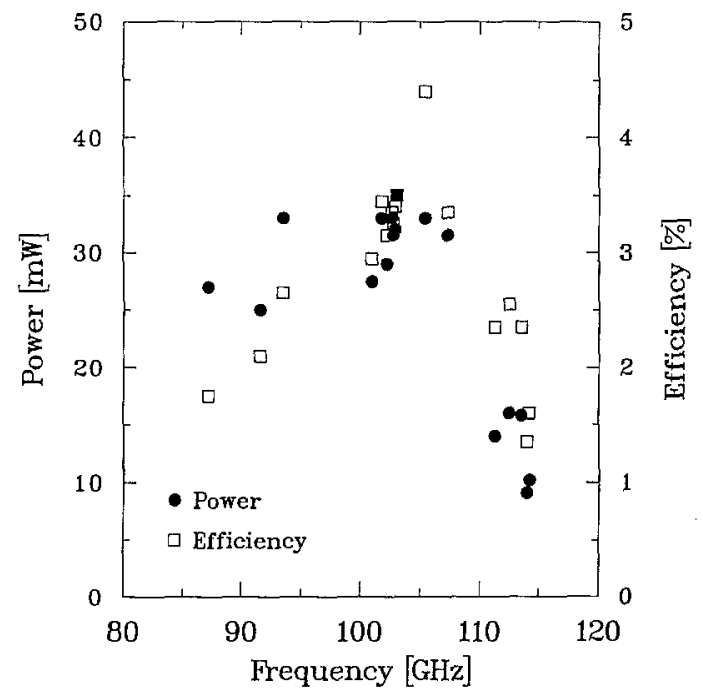

Fig. 3. Output power and efficiency versus oscillation frequency for different GaAs W-band single-drift TUNNETT diodes

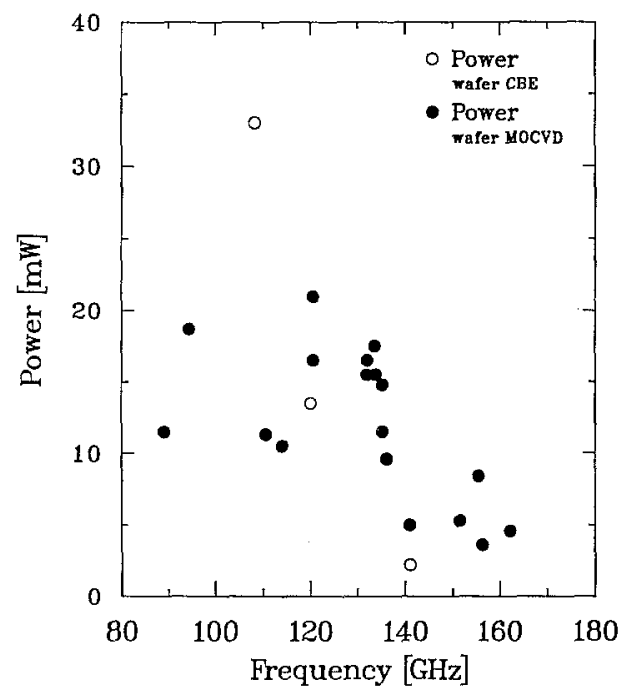

Fig. 4. Output power versus oscillation frequency for different $\operatorname{InP}$ D-band Gunn devices in W-band and D-band

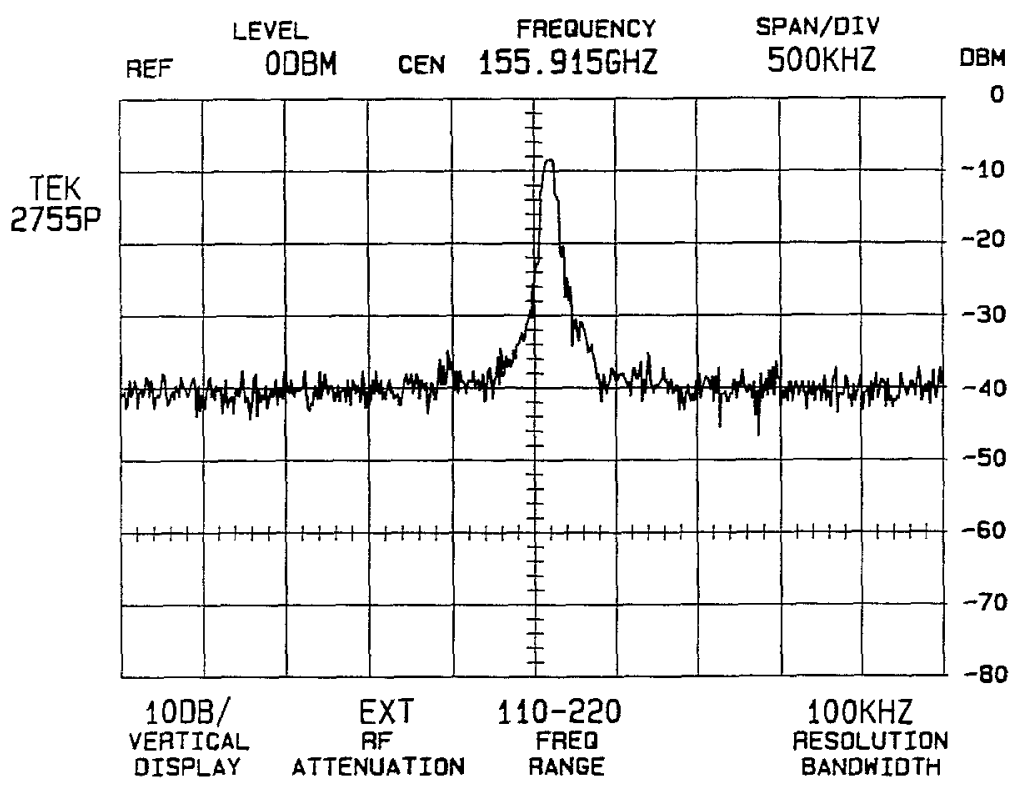

Fig. 5. Spectrum of an InP D-band Gunn device free running oscillator, power level $3.6 \mathrm{~mW}$, center frequency $155.915 \mathrm{GHz}$, vertical scale $10 \mathrm{~dB} / \mathrm{div}$, horizontal scale $500 \mathrm{kHz} / \mathrm{div}, \mathrm{BW} 100 \mathrm{kHz}$ summarizes the experimental results for the eleven best devices of the W-band TUNNETT diodes that have been mounted and tested to date. The peak in output power $(35 \mathrm{~mW})$ and efficiency $(>4 \%)$ at around $103 \mathrm{GHz}$ occurs close to the design frequency of $100 \mathrm{GHz}$ and confirms that the first order design rules [5] accurately predict the operating frequency of the TUNNETT diodes. It also indicates that the average, high field, high temperature electron drift velocity in GaAs TUNNETT diodes is close to $4.6 \times 10^{6} \mathrm{cms}^{-1}$ [7].

Figure 4 compares the experimental results obtained from the InP Gunn devices with the flat doping profile (grown by $\mathrm{CBE}$ ) and with the graded doping profile (grown by MOCVD) between about $90 \mathrm{GHz}$ and $165 \mathrm{GHz}$. The best device with the flat doping profile yielded an RF output power of $33 \mathrm{~mW}$ with a corresponding dc to $\mathrm{RF}$ conversion efficiency of $1.75 \%$ at $108.3 \mathrm{GHz}$. To the authors' knowledge, these are the highest reported values for an $\mathrm{n}^{+} \mathrm{n}^{-} \mathrm{n}^{+}$structure. As expected from the simulations, devices with the graded doping profile exhibit the better performance. RF output power levels of $21 \mathrm{~mW}$ at $120.6 \mathrm{GHz}, 17.5 \mathrm{~mW}$ at $133.7 \mathrm{GHz}$ and $8.4 \mathrm{~mW}$ at $155.4 \mathrm{GHz}$ were obtained from the best devices so far. The corresponding dc to RF conversion efficiencies were $1.25 \%, 1 \%$ and $0.6 \%$, respectively. Oscillations up to about $165 \mathrm{GHz}(<1 \mathrm{~mW})$ have also been detected in a reduced-height WR-4 waveguide cavity with a coaxial post.

All investigated IMPATT diodes, TUNNETT diodes and Gunn devices exhibit clean spectra up to the highest oscillation frequencies. As an example the spectrum of a free running Gunn device oscillator is shown in Fig. 5 for $3.6 \mathrm{~mW}$ at $156 \mathrm{GHz}$. Using a self-injection locking method a loaded $Q$ value of 54 was measured at $156 \mathrm{GHz}$. This low a value indicates that the Gunn device operates in the fundamental-frequency mode. Typical loaded $Q$ values between 30 and 105 were determined for various Gunn devices with the two doping profiles at other D-band frequencies and corroborate this conclusion. 


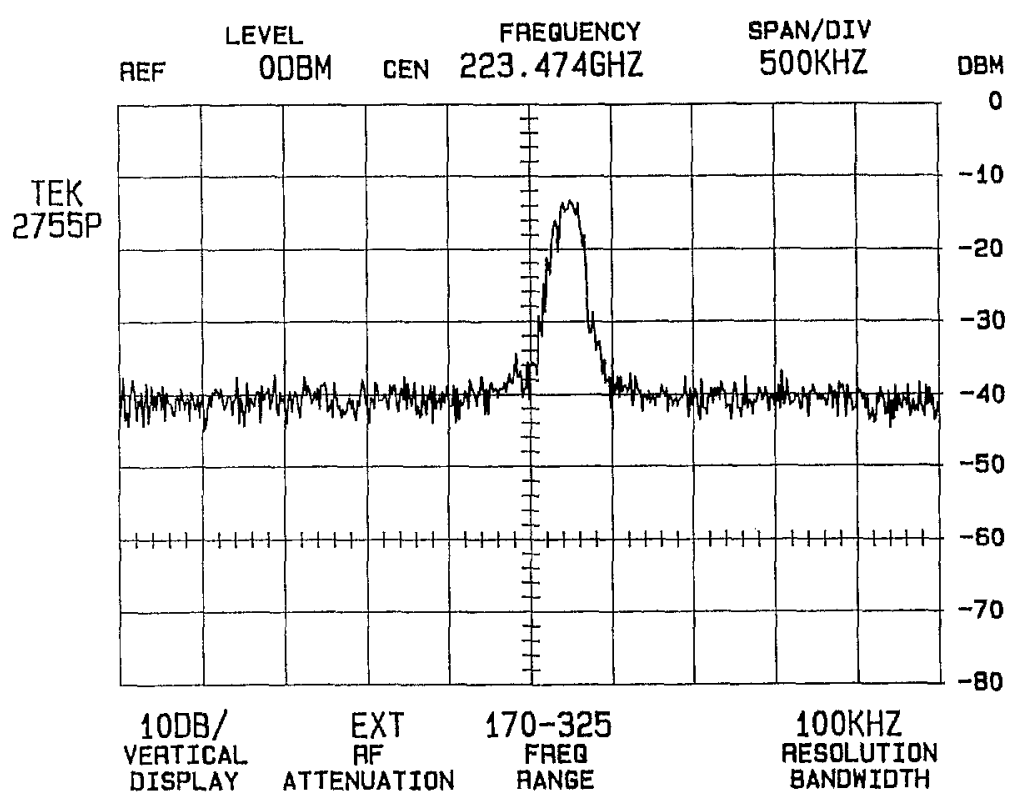

Fig. 6. Spectrum of a W-band TUNNETT diode free running oscillator in second harmonic mode, power level $0.2 \mathrm{~mW}$, center frequency $223.474 \mathrm{GHz}$, vertical scale $10 \mathrm{~dB} / \mathrm{div}$, horizontal scale $500 \mathrm{kHz} / \mathrm{div}, \mathrm{BW} 100 \mathrm{kHz}$

\section{Second harmonic power extraction}

IMPATT diodes, TUNNETT diodes and Gunn devices are nonlinear devices and are expected to have higher harmonics in their output signal. Therefore, a $1^{\prime \prime}$-long WR-3 waveguide section (cut-off frequency: $173.28 \mathrm{GHz}$ ) was inserted between a D-band thermistor power head (calibrated around $160 \mathrm{GHz}$ ) and the flange of the full height waveguide cavity. Estimated $3 \mathrm{~dB}$ attenuation were taken into account for the losses in the three waveguide sections (each 1" long) and for the mismatch in the power head, although the correction factor for the D-band thermistor head might be considerably higher at around $220 \mathrm{GHz}$.

A W-band IMPATT diode with a maximum RF output power of $140 \mathrm{~mW}$ and a dc to RF conversion efficiency of $4.2 \%$ at $93.4 \mathrm{GHz}$ yielded an output power of $0.12 \mathrm{~mW}$ at a second harmonic frequency of about $182 \mathrm{GHz}$ and a bias current of about $2 / 3$ the maximum bias current. A D-band IMPATT diode with $20 \mathrm{~mW}$ at $120 \mathrm{GHz}$ had an output power of $13 \mu \mathrm{W}$ at the second harmonic of $240 \mathrm{GHz}$. An explanation of low up-conversion efficiency can be found in the decrease of the derivative of the ionization rates with respect to the electric field strength at electric fields above $500 \mathrm{kV} \mathrm{cm}^{-1}[4,10]$. This decrease causes the avalanche process to become more and more linear [10] and the higher harmonics to disappear in the output signal of the diode.

Three different D-band Gunn devices yielded RF output power levels of $0.39 \mathrm{~mW}$ at $220 \mathrm{GHz}$ with a fundamental to second-harmonic power conversion efficiency of $2.5 \%, 0.09 \mathrm{~mW}$ at $228 \mathrm{GHz}$ and $0.12 \mathrm{~mW}$ at $232 \mathrm{GHz}$. The power levels are similar to the values obtained with a more optimized second-harmonic oscillator circuit [11]. A W-band InP Gunn device tested in a full-height WR-10 waveguide gave $3.5 \mathrm{~mW}$ at $156.3 \mathrm{GHz}$ with a fundamental to second-harmonic power conversion efficiency of $10 \%$. The second harmonic output of this W-band oscillator was measured in a WR-6 waveguide test setup.

Four different TUNNETT diodes had RF power levels of $41 \mu \mathrm{W}$ at $200 \mathrm{GHz}, 0.25 \mathrm{~mW}$ at $223.5 \mathrm{GHz}$ and
$223 \mathrm{GHz}$ and $0.12 \mathrm{~mW}$ at $225 \mathrm{GHz}$. The RF output power level of the TUNNETT diode with the $0.25 \mathrm{~mW}$ at the second harmonic was $14 \mathrm{~mW}$ at $112.5 \mathrm{GHz}$. Thus a conversion efficiency of $1.8 \%$ between fundamental and second-harmonic output power can be calculated. This value is very similar to the unpublished result of a Vband TUNNETT diode which had a conversion efficiency of $2 \%$ and an output power of $0.5 \mathrm{~mW}$ at the secondharmonic frequency of $121 \mathrm{GHz}$. The V-band diode was tested in a full-height WR-15 waveguide cavity [12] and the second-harmonic output was measured in a WR- 6 test setup. Figure 6 shows the spectrum of the W-band TUNNETT diode at an RF output power of $0.2 \mathrm{~mW}$ and proves that the oscillations have a clean spectrum even at the second harmonic of $223.5 \mathrm{GHz}$. This is the highest reported frequency for CW operation of TUNNETT diodes.

\section{Conclusion}

The experimental results from the D-band IMPATT diodes are the best reported to date. The power levels and efficiencies of the W-band TUNNETT diodes above $93.5 \mathrm{GHz}$ are the highest reported so far and compare favorably to the values of Gunn devices [13-15] above $100 \mathrm{GHz}$. InP Gunn devices can be operated in fundamental mode up to D-band frequencies exceeding the power levels that have been published so far. These experimental results confirm recent theoretical findings. Free running oscillators with all these two-terminal devices exhibit clean spectra which makes them excellent candidates for local oscillator applications.

Second harmonic power extraction has been successfully demonstrated with IMPATT diodes, TUNNETT diodes and Gunn devices. Useful power levels with clean spectra were extracted from TUNNETT diodes and Gunn devices. Higher power levels and harmonic power extraction at higher frequencies can be expected with more optimized circuits. 


\section{Acknowledgements}

The authors wish to thank Y. Saito at TRW and Jürg M. Siegenthaler at the Swiss PTT for providing different metallized quartz rings which were used to package some of the Gunn devices. The authors would also like to thank P. Siegel at JPL for making the WR-4 waveguide cavity available. This work was supported by NASA under contract No. NAGW 1334.

\section{References}

1. Schellenberg, J. M.; Lau, C. L.; Feng, M.; Brusenback, P.: W-band oscillator using ion-implanted InGaAs MESFET's. IEEE Microwave and Guided Wave Letters MGWL-1(5) (1991) $100-102$

2. Kwon, Y.; Pavlidis, D.; Tutt, M.; Ng, G. I.; Lai, R.; Brock, T.: W-band monolithic oscillator using InAlAs/InGaAs HEMT's. Electronics Letters 26 (18) (1990) 1425-1426

3. Kamoua, R.; Eisele, H.; Haddad, G. I.: D-band InP Gunn devices. To appear in Solid-State Electronics, 1993

4. Eisele, H.: GaAs W-band IMPATT diodes: The first step to higher frequencies. Microwave Journal 34 (1991) 275-282

5. Haddad, G. I.; East, J. R.; Kidner, C.: Tunnel transit-time (TUNNETT) devices for terahertz sources. Microwave and Optical Technology Letters 4 (1991) 23-29

6. Eisele, H.: Electron properties in GaAs for the design of mm-wave IMPATTS. International Journal of Infrared and Millimeter Waves 4 (1991) 345-354

7. Eisele, H.; Kidner, C.; Hadded, G. I.: A CW GaAs TUNNETT diode source for $100 \mathrm{GHz}$ and above. Proceedings of the 22nd European Microwave Conference, Helsinki, Finland (1992) $467-472$

8. Eisele, H.: Selective etching technology for $94 \mathrm{GHz}$ GaAs IMPATT diodes on diamond heat sinks. Solid-State Electronics 32 (1989) 253-257

9. Eisele, H.; Hadded, G. I.: GaAs single-drift flat-profile IMPATT diodes for $\mathrm{CW}$ operation in D-band. Electronics Letters 28 (1992) $2176-2177$

10. Rolland, P. A.; Friscourt, M. R.; Lippens, D.; Dalle, C.; Nieruchalski, J. L.: Millimeter wave solid-state power sources. Proceedings of the International Workshop on Millimeter Waves, Rome, Italy (1986) 125-177

11. Rydberg, A.: High efficiency and output power from second- and third-harmonic millimeter-wave InP-TED oscillators at frequencies above $170 \mathrm{GHz}$. IEEE Electron Dev. Letters EDL-11 (1990) 439-441

12. Kidner, C.; Eisele, H.; East, J.; Haddad, G. I.: Design, fabrication and evaluation of tunnel transit-time diodes for V-band and W-band power generation. Proceedings of the 1992 IEEE MTT-S International Microwave Symposium, Albuquerque, New Mexico (1992) 1089-1092

13. Wandinger, L.: mm-wave InP Gunn devices: status and trends. Microwave Journal, 24 (1981) $71-78$

14. Eddison, I. G. et al.: Efficient fundamental frequency oscillation from $m m$-wave $I n P n^{+}-n-n^{+}$TEOs. Electronics Letters 17 (1981) $758-760$

15. Teng, S. J. J.; Goldwasser, R. E.: High performance secondharmonic operation W-band GaAs Gunn diodes. IEEE Electron Device Letters EDL-10 (1989) 412-414

Received July 13, 1993

H. Eisele, G. I. Haddad, C. Kidner

Center for Space Terahertz Technology

Department of Electrical Engineering \& Computer Science

The University of Michigan

Ann Arbor, Michigan 48109-2122

USA

R. Kamoua

Department of Electrical Engineering

State University of New York at Stony Brook

Stony Brook, NY 11794-2350

USA 